\title{
The Association between Childhood Overweight and Reflux Esophagitis
}

\author{
Nirav R. Patel, ${ }^{1}$ Mary J. Ward, ${ }^{2}$ Debra Beneck, ${ }^{3}$ Susanna Cunningham-Rundles, ${ }^{4}$ \\ and Aeri Moon ${ }^{1,5}$ \\ ${ }^{1}$ Division of Gastroenterology and Nutrition, Department of Pediatrics, New York-Presbyterian Hospital, Weill Cornell Medical College, \\ Cornell University, New York, NY 10065, USA \\ ${ }^{2}$ Division of General Pediatrics, Department of Pediatrics, New York-Presbyterian Hospital, Weill Cornell Medical College, \\ Cornell University, New York, NY 10065, USA \\ ${ }^{3}$ Department of Pathology, New York-Presbyterian Hospital, Weill Cornell Medical College, Cornell University, New York, \\ NY 10065, USA \\ ${ }^{4}$ Division of Hematology and Oncology, Department of Pediatrics, New York-Presbyterian Hospital, Weill Cornell Medical College, \\ Cornell University, New York, NY 10065, USA \\ ${ }^{5}$ Division of Gastroenterology \& Nutrition, Massachusetts General Hospital for Children, 175 Cambridge Street, CPZS-558, Boston, \\ MA 02114, USA
}

Correspondence should be addressed to Aeri Moon, amoon@partners.org

Received 8 December 2009; Revised 28 February 2010; Accepted 28 February 2010

Academic Editor: Jack Adam Yanovski

Copyright (c) 2010 Nirav R. Patel et al. This is an open access article distributed under the Creative Commons Attribution License, which permits unrestricted use, distribution, and reproduction in any medium, provided the original work is properly cited.

\begin{abstract}
Background. In adults, it has been shown that obesity is associated with gastroesophageal reflux disease (GERD) and GERD-related complications. There are sparse pediatric data demonstrating associations between childhood overweight and GERD. Objective. To investigate the association between childhood overweight and RE. Methods. We performed a retrospective chart review of 230 children $(\mathrm{M}: \mathrm{F}=114: 116)$ who underwent esophagogastroduodenoscopy (EGD) with biopsies between January 2000 and April 2006. Patient demographics, weight, height, clinical indications for the procedure, the prevalence of BMI classification groups, the prevalence of RE and usage of anti-reflux medications were reviewed. For these analyses, the overweight group was defined to include subjects with BMI $\geq 85$ th percentile. The normal weight group was defined to include subjects with BMI 5th to 85th percentile. Results. Among the 230 subjects, 67 (29.1\%) had BMI percentiles above the 85th percentile for age and gender. The prevalence of RE in the overweight group did not differ significantly from that in the normal weight group $(23.9 \%$ versus $24.5 \%$, resp.). Overweight subjects taking anti-reflux medications clearly demonstrated a higher prevalence of biopsy-proven RE compared to overweight subjects not taking anti-reflux medications $(34.1 \%$ versus $7.7 \%, P=.009)$. Conclusions. There was no significant difference in the prevalence of biopsy-proven RE in the overweight group compared to the normal weight group. However, the prevalence of RE was significantly higher in overweight subjects on anti-reflux medications compared to overweight subjects not taking anti-reflux medications. This finding emphasizes the importance of early recognition and treatment of GERD for the overweight pediatric patients with symptoms in conjunction with weight loss program for this population to reduce long-term morbidities associated with GERD.
\end{abstract}

\section{Introduction}

Obesity is now regarded as a disease of epidemic proportions in the United States. Data from the National Health and Nutrition Examination Survey (NHANES) demonstrate that the prevalence of overweight in children and adolescents has been rising at a staggering rate during the last several decades
$[1,2]$. The 2003-to-2004 survey indicated that approximately 17 percent of children and adolescents aged 2 to 19 years were overweight. This represents a dramatic increase from the NHANES III (1988 to 1994) overweight figure of 11 percent. The finding that overweight children are at risk of becoming overweight adults [3] is especially concerning given that overweight adults have elevated risks of developing metabolic 
and cardiac disorders [4]. In particular, abdominal obesity has been linked to serious morbidities, such as diabetes mellitus [5], heart disease [6], and certain cancers [7]. The health implications of childhood overweight have served as an impetus for major public health concern in the United States.

In adults, obesity and overweight are independent risk factors for gastroesophageal reflux disease (GERD) and endoscopy-proven esophageal erosions [8]. Adults with chronic GERD are at risk of developing associated complications, such as erosive esophagitis [9], Barrett's esophagus [10] and adenocarcinoma of the esophagus [11]. There is a growing body of evidence that illustrates the association between increasing body mass index (BMI) and GERD. Cross-sectional studies and meta-analyses have confirmed this association in adult subjects $[12,13]$. A few studies have established a clear dose-dependent relationship between increasing BMI and GERD symptoms [8, 14, 15]. Similar data in the pediatric literature are sparse. A study published by Størdal et al. in 2006 demonstrated an association between increasing BMI and GERD in children aged 7 to 16 years, as reported by symptoms or $\mathrm{pH}$ monitoring abnormalities [16]. A recent retrospective review by Elitsur et al. did not reveal a greater prevalence of RE in children who were overweight or obese compared to those with normal weight [17]. In this study, we evaluated the association between RE and overweight in children, instead of clinical symptoms or endoscopic findings consistent with GERD. A study published by Zentilin et al. in 2005 showed that histology could provide useful and objective additional data in patients with nonerosive reflux disease [18]. Furthermore, Lombardi et al. suggested that esophageal biopsies are very important aids in the diagnosis of esophagitis since clinical symptoms of GERD or endoscopic visual findings do not always correlate with histologic abnormalities [19].

\section{Patients and Methods}

2.1. Patients. A retrospective chart review of all patients between the ages of 2 and 20 years who underwent upper endoscopies with biopsies at New York Weill Cornell Medical Center between January 2000 and April 2006 was carried out. The following exclusion criteria were used: (1) procedures with absence of esophageal biopsies, (2) repeated upper endoscopies on already-included subjects, (3) unavailability of all required information (e.g., anthropometric data at the time of procedure), and (4) subjects with BMI $<5 \%$ ile. Charts were reviewed for the following data: age, gender, weight, height, indication for the procedure, presence of RE, and usage of antireflux medications (proton pump inhibitors or $\mathrm{H}_{2}$ receptor antagonists) at the time of the procedure for at least 10 days. Weight and height were used to calculate BMI percentiles on 2000 Centers for Disease Control sexspecific BMI-for-age growth charts, which define BMI $\geq$ 95th percentile to be overweight and $\mathrm{BMI} \geq 85$ th percentile and $<95$ th percentile to be at risk for overweight [20]. $\mathrm{BMI} \geq 85$ th percentile was classified as overweight for the purpose of this study. Age- and gender-specific $z$-scores for weight and BMI were calculated. Two hundred thirty patients were included in this study, and detailed characterization and analysis of these subjects $(\mathrm{M}: \mathrm{F}=114: 116)$ were conducted. The mean age of the study sample was 11.3 years. The indication for the procedures in order of prevalence was as follows: recurrent abdominal pain $(n=151,65.6 \%)$, clinical GERD symptoms $(n=51,22.2 \%)$, weight loss ( $n=18,7.8 \%)$, conditions such as upper GI bleeding or IBD surveillance $(n=8,3.5 \%)$, and suspected allergic gastrointestinal disorders $(n=2,0.9 \%)$.

2.2. Endoscopy and Biopsy. All endoscopies were performed using video gastroscopes (Pentax, Japan) EG1840, EG2430, or EG2731. Biopsy specimens were taken from the gastric antrum and distal esophagus during the procedure. The specimens were immediately fixed in $10 \%$ buffered formalin solution, embedded in paraffin, cut at 4-6 microns thick, and stained with hematoxylin-eosin (H\&E) for histologic evaluation. A diagnosis of RE was based on histologic findings of basal cell hyperplasia with eosinophilic exocytosis (in the absence of such findings in the upper esophagus). All esophageal biopsy slides were reevaluated by a single pathologist, for grading of the esophagitis using a modification of the scale suggested by Zentilin et al. [18]. Biopsy specimens were graded on a 4 -point scale; $0 / 3=$ normal, no basal cell hyperplasia, minimal (less than 3 eosinophils/high power field (HPF) exocytosis; $1 / 3=$ mild (up to $1 / 3$ of epithelial thickness) basal cell hyperplasia, minimal to mild (between 2 and 8 eosinophils/HPF) exocytosis (mild active esophagitis); $2 / 3=$ moderate (from $1 / 3$ to $2 / 3$ of epithelial thickness) basal cell hyperplasia, moderate (between 10 and 15 eosinophils/HPF) exocytosis (moderate active esophagitis); $3 / 3=$ marked ( $2 / 3$ to full-thickness) basal cell hyperplasia, marked (over 20 eosinophils/HPF) exocytosis (severe active esophagitis) [21].

The study was approved by the Institutional Review Board of Weill Medical College of Cornell University.

\section{Statistics}

Comparisons between groups were performed using the uncertainty coefficient. $P$-value of $<.05$ was accepted as indicating statistical significance. All statistical analyses were performed using commercially available computer software (SPSS for Windows).

\section{Results}

A total of 230 subjects were included in the study (Table 1). The mean age was 11.3 years (s.d. $=4.7$ years), and 114 $(49.6 \%)$ were male. Forty-two percent of the subjects were between 2 and 10 years of age and 58\% from 11 to 20 years. A total of 163 subjects were classified as normal BMI (70.9\%), 29 as at risk for overweight (12.6\%), and 38 as overweight (16.5\%); therefore $67(29.1 \%)$ were defined as overweight. Symptoms of clinical GERD were the indication for endoscopy in $22.2 \%$ of subjects. Histologic evidence of $\mathrm{RE}$ was seen in $24.3 \%$ of subjects. The majority of subjects 
TABLE 1: Characteristics of study population.

\begin{tabular}{lc}
\hline Characteristics & Number of patients \\
\hline Study population & 230 \\
\hline Age & \\
2-10 years & $97(42.2 \%)$ \\
11-19 years & $133(57.8 \%)$ \\
\hline Gender & \\
Female & $116(50.4 \%)$ \\
Male & $114(49.6 \%)$ \\
\hline Indications & \\
Abdominal pain & $151(65.7 \%)$ \\
Clinical GERD symptoms & $51(22.2 \%)$ \\
Weight loss & $18(7.8 \%)$ \\
Other (UGI bleeding, Crohn's disease) & $8(3.5 \%)$ \\
Rule out allergy & $2(0.8 \%)$ \\
\hline BMI & $163(70.9 \%)$ \\
Normal BMI (5\%-85\%ile) & $29(12.6 \%)$ \\
At risk for overweight (85-95\%ile) & $38(16.5 \%)$ \\
Overweight (>95\%ile) & $174(75.7 \%)$ \\
\hline RE & $56(24.3 \%)$ \\
No & $101(43.9 \%)$ \\
Yes & $129(56.1 \%)$ \\
\hline Antireflux medication use & \\
No & \\
Yes & \\
\hline
\end{tabular}

TABLE 2: Comparison between BMI group and presence of RE.

\begin{tabular}{lccc}
\hline & Normal BMI & Overweight & $P$-value \\
\hline $\begin{array}{l}\text { Presence of RE } \\
\text { No }\end{array}$ & 123 & 51 & \\
Yes & $40(24.5 \%)$ & $16(23.9 \%)$ & .916 \\
\hline
\end{tabular}

TABLE 3: Comparison of RE based on antireflux medication use and BMI group.

\begin{tabular}{lrcc}
\hline & \multicolumn{2}{c}{ RE } & \multirow{2}{*}{ P-value } \\
& No & Yes & \\
\hline Medication use in normal weight group & & & \\
No & 58 & $17(22.7 \%)$ & .607 \\
Yes & 65 & $23(26.1 \%)$ & \\
\hline Medication use in overweight group & & & \\
No & 24 & $2(7.7 \%)$ & .009 \\
Yes & 27 & $14(34.1 \%)$ & \\
\hline
\end{tabular}

in this study $(129,56.1 \%)$ were on antireflux therapy at the time of endoscopy.

As evident in Table 2, the prevalence of $\mathrm{RE}$ in the overweight group did not differ significantly from that in the normal weight group (23.9\% versus $24.5 \%$, resp.). Overweight subjects taking antireflux medications demonstrated a higher prevalence of biopsy-proven RE compared to overweight subjects not taking antireflux medications (34.1\% versus $7.7 \%, P=.009$ ), as seen in Table 3 .
TABLE 4: Prevalence of RE and overweight based on age group

\begin{tabular}{lccc}
\hline & $2-10$ years & $11-19$ years & $P$-value \\
\hline$R E$ & & & \\
No & 66 & 108 & .022 \\
Yes & $31(32.0 \%)$ & $25(18.8 \%)$ & \\
\hline $\begin{array}{l}\text { Overweight } \\
\text { No }\end{array}$ & 60 & 103 & \\
Yes & $37(38.1 \%)$ & $30(22.6 \%)$ & .010 \\
\hline
\end{tabular}

A secondary analysis based on age (Table 4) comparing prepubertal subjects (2 to 10 years) to older subjects (11 to 19 years) showed that the younger subjects had a higher prevalence of both RE $(32.0 \%$ versus $18.8 \%, P=.022)$ and overweight (38.1\% versus $22.6 \%, P=.010)$.

\section{Discussion}

Our study does not suggest that there is a greater prevalence of RE among overweight children. There was no doseresponse relationship between GERD symptoms and increasing BMI category. However the analyses did reveal that the overweight subjects on antireflux therapy had a significantly higher prevalence of biopsy-proven RE as compared to the overweight subjects not taking antireflux medications. This finding may suggest that higher-BMI patients with symptomatology necessitating antireflux therapy should be targeted for aggressive therapy, and weight loss should be advocated to mediate this effect.

Numerous adult studies have demonstrated a positive correlation between obesity and GERD by using clinical gastroesophageal symptoms and esophageal $\mathrm{pH}$ monitoring in relation to obesity $[14,15,22-27]$. The finding of endoscopically detected RE has been a useful endpoint in studies investigating the relationship between GERD and obesity $[8,22,23]$. As mentioned earlier, our study used the prevalence of RE instead of symptomatology or endoscopic appearance consistent with GERD.

Our study did not support the positive relationship between BMI and GERD in children and adolescents, it is consistent with the findings published by Elitsur et al. [17]. Several theories may help to explain the lack of direct correlation between increasing BMI and RE in our pediatric sample. The cumulative length of time of esophageal acid exposure may be greater in adults with long-standing overweight, as compared to in children, leading to more clinically relevant GERD symptoms and greater mucosal damage and esophagitis. Since overweight subjects are at higher risk of developing both acid and nonacid reflux diseases [28], the use of multichannel intraluminal impedance (MII) monitoring may be useful to investigate this relationship in future prospective trials.

High percentage of our patients $(56.1 \%)$ was using antireflux medications at the time of endoscopy and it is conceivable that we could have underestimated the true prevalence of RE in our population, both the overweight and normal weight groups. We did not exclude patients 
with confounding factors that are known to increase the risk of developing GERD, such as those with neuromuscular disorders, Down syndrome, and chronic pulmonary conditions. We did not perform $\mathrm{pH}$ probe study or MII monitoring to detect acid reflux as well as nonacid reflux since this was a retrospective study. Furthermore, given the reliability of waist circumference as a marker of visceral adiposity, it may have been more favorable to utilize this measure to investigate the relationship between overweight and GERD.

In summary, our study showed no significant difference in the prevalence of biopsy-proven $\mathrm{RE}$ in the overweight group compared to the normal weight group in children. However, future prospective trials utilizing tools to measure acid as well as non-acid reflux (such as MII) may be useful to better understand this relationship.

\section{References}

[1] C. L. Ogden, M. D. Carroll, L. R. Curtin, M. A. McDowell, C. J. Tabak, and K. M. Flegal, "Prevalence of overweight and obesity in the United States, 1999-2004," Journal of the American Medical Association, vol. 295, no. 13, pp. 1549-1555, 2006.

[2] C. L. Ogden, K. M. Flegal, M. D. Carroll, and C. L. Johnson, "Prevalence and trends in overweight among US children and adolescents, 1999-2000," Journal of the American Medical Association, vol. 288, no. 14, pp. 1728-1732, 2002.

[3] R. C. Whitaker, J. A. Wright, M. S. Pepe, K. D. Seidel, and W. H. Dietz, "Predicting obesity in young adulthood from childhood and parental obesity," New England Journal of Medicine, vol. 337, no. 13, pp. 869-873, 1997.

[4] A. Must, J. Spadano, E. H. Coakley, A. E. Field, G. Colditz, and W. H. Dietz, "The disease burden associated with overweight and obesity," Journal of the American Medical Association, vol. 282, no. 16, pp. 1523-1529, 1999.

[5] E. J. Boyko, W. Y. Fujimoto, D. L. Leonetti, and L. NewellMorris, "Visceral adiposity and risk of type 2 diabetes: a prospective study among Japanese Americans," Diabetes Care, vol. 23, no. 4, pp. 465-471, 2000.

[6] M. Dalton, A. J. Cameron, P. Z. Zimmet, et al., "Waist circumference, waist-hip ratio and body mass index and their correlation with cardiovascular disease risk factors in Australian adults," Journal of Internal Medicine, vol. 254, no. 6, pp. 555-563, 2003.

[7] E. Giovannucci, "Obesity, gender, and colon cancer," Gut, vol. 51, no. 2, p. 147, 2002.

[8] H. B. El-Serag, D. Y. Graham, J. A. Satia, and L. Rabeneck, "Obesity is an independent risk factor for GERD symptoms and erosive esophagitis," American Journal of Gastroenterology, vol. 100, no. 6, pp. 1243-1250, 2005.

[9] H. B. El-Serag and J. F. Johanson, "Risk factors for the severity of erosive esophagitis in Helicobacter pylori-negative patients with gastroesophageal reflux disease," Scandinavian Journal of Gastroenterology, vol. 37, no. 8, pp. 899-904, 2002.

[10] B. J. Reid and W. M. Weinstein, "Barrett's esophagus and adenocarcinoma," Annual Review of Medicine, vol. 38, pp. 477-492, 1987.

[11] J. Lagergren, R. Bergström, A. Lindgren, and O. Nyrén, "Symptomatic gastroesophageal reflux as a risk factor for esophageal adenocarcinoma," New England Journal of Medicine, vol. 340, no. 11, pp. 825-831, 1999.

[12] H. Hampel, N. S. Abraham, and H. B. El-Serag, "Metaanalysis: obesity and the risk for gastroesophageal reflux disease and its complications," Annals of Internal Medicine, vol. 143, no. 3, pp. 199-211, 2005.

[13] D. A. Corley and A. Kubo, "Body mass index and gastroesophageal reflux disease: a systematic review and metaanalysis," American Journal of Gastroenterology, vol. 101, no. 11, pp. 2619-2628, 2006.

[14] G. R. Locke III, N. J. Talley, S. L. Fett, A. R. Zinsmeister, and L. J. Melton III, "Risk factors associated with symptoms of gastroesophageal reflux," American Journal of Medicine, vol. 106, no. 6, pp. 642-649, 1999.

[15] L. Murray, B. Johnston, A. Lane, et al., "Relationship between body mass and gastro-oesophageal reflux symptoms: the Bristol Helicobacter Project," International Journal of Epidemiology, vol. 32, no. 4, pp. 645-650, 2003.

[16] K. Størdal, G. B. Johannesdottir, B. S. Bentsen, K. C. L. Carlsen, and L. Sandvik, "Asthma and overweight are associated with symptoms of gastro-oesophageal reflux," Acta Paediatrica, vol. 95, no. 10, pp. 1197-1201, 2006.

[17] Y. Elitsur, Y. Dementieva, R. Elitsur, and M. Rewalt, “Obesity is not a risk factor in children with reflux esophagitis: a retrospective analysis of 738 children," Metabolic Syndrome and Related Disorders, vol. 7, no. 3, pp. 211-214, 2009.

[18] P. Zentilin, V. Salvarino, L. Mastracci, et al., "Reassessment of the diagnostic value of histology in patients with GERD, using multiple biopsy sites and an appropriate control group," American Journal of Gastroenterology, vol. 100, no. 10, pp. 2299-2306, 2005.

[19] G. Lombardi, G. de’ Angelis, V. Rutigliano, et al., "Reflux oesophagitis in children; the role of endoscopy. A multicentric Italian survey," Digestive and Liver Disease, vol. 39, no. 9, pp. 864-871, 2007.

[20] R. J. Kuczmarski, C. L. Ogden, L. M. Grummer-Strawn, et al., "CDC growth charts: United States," Advance Data, no. 314, pp. 1-27, 2000.

[21] A. Moon, A. Solomon, D. Beneck, and S. CunninghamRundles, "Positive association between helicobacter pylori and gastroesophageal reflux disease in children," Journal of Pediatric Gastroenterology and Nutrition, vol. 49, no. 3, pp. 283-288, 2009.

[22] B. L. Fisher, A. Pennathur, J. L. Mutnick, and A. G. Little, "Obesity correlates with gastroesophageal reflux," Digestive Diseases and Sciences, vol. 44, no. 11, pp. 2290-2294, 1999.

[23] S. A. Wajed, C. G. Streets, C. G. Bremner, and T. R. DeMeester, "Elevated body mass disrupts the barrier to gastroesophageal reflux," Archives of Surgery, vol. 136, no. 9, pp. 1014-1019, 2001.

[24] H. B. El-Serag, G. A. Ergun, J. Pandolfino, S. Fitzgerald, T. Tran, and J. R. Kramer, "Obesity increases oesophageal acid exposure," Gut, vol. 56, no. 6, pp. 749-755, 2007.

[25] B. C. Jacobson, S. C. Somers, C. S. Fuchs, C. P. Kelly, and C. A. Camargo Jr., "Body-mass index and symptoms of gastroesophageal reflux in women," New England Journal of Medicine, vol. 354, no. 22, pp. 2340-2348, 2006.

[26] S. Nandurkar, G. R. Locke III, S. Fett, A. R. Zinsmeister, A. J. Cameron, and N. J. Talley, "Relationship between body mass index, diet, exercise and gastro-oesophageal reflux symptoms in a community," Alimentary Pharmacology and Therapeutics, vol. 20, no. 5, pp. 497-505, 2004. 
[27] M. Nilsson, R. Johnsen, W. Ye, K. Hveem, and J. Lagergren, "Obesity and estrogen as risk factors for gastroesophageal reflux symptoms," Journal of the American Medical Association, vol. 290, no. 1, pp. 66-72, 2003.

[28] J. M. E. Schneider, B. L. D. M. Brucher, M. Kuper, et al., "Multichannel intrluminal impedance measurement of gastroesophageal reflux in patients with different stages of morbid obesity," Obesity Surgery, vol. 19, pp. 1522-1529, 2009. 


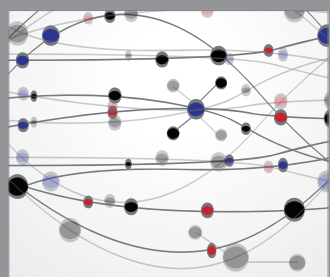

The Scientific World Journal
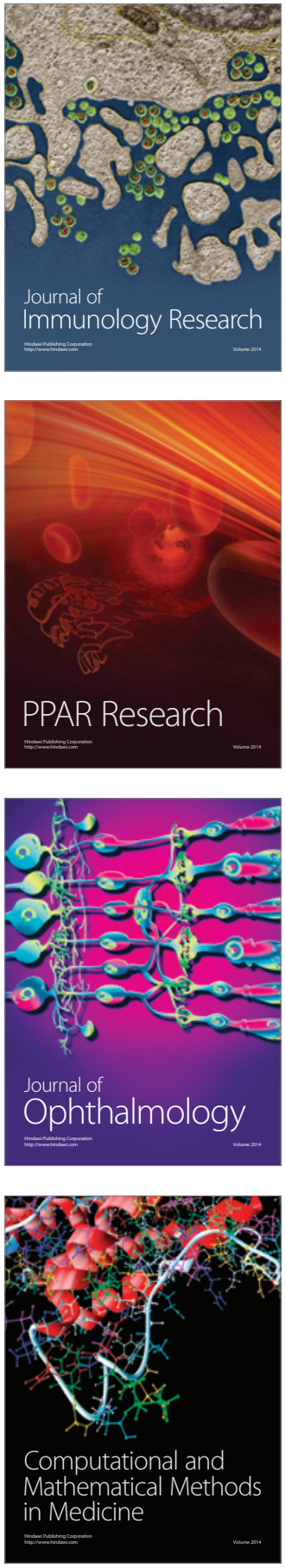

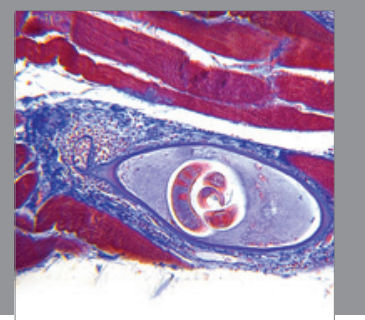

Gastroenterology

Research and Practice
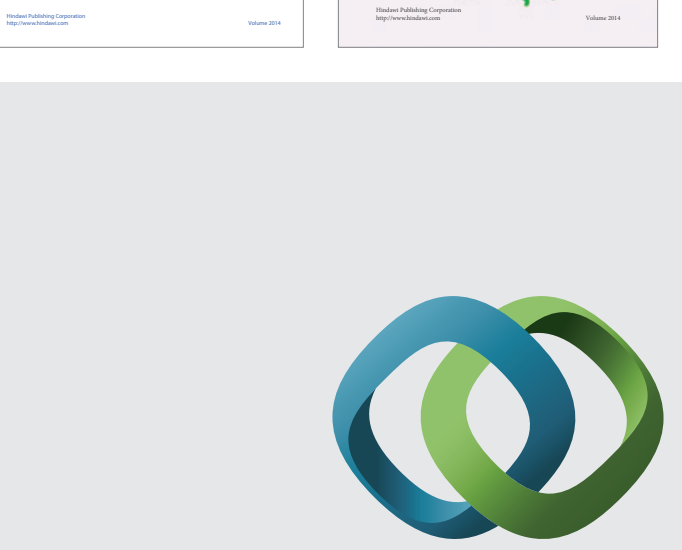

\section{Hindawi}

Submit your manuscripts at

http://www.hindawi.com
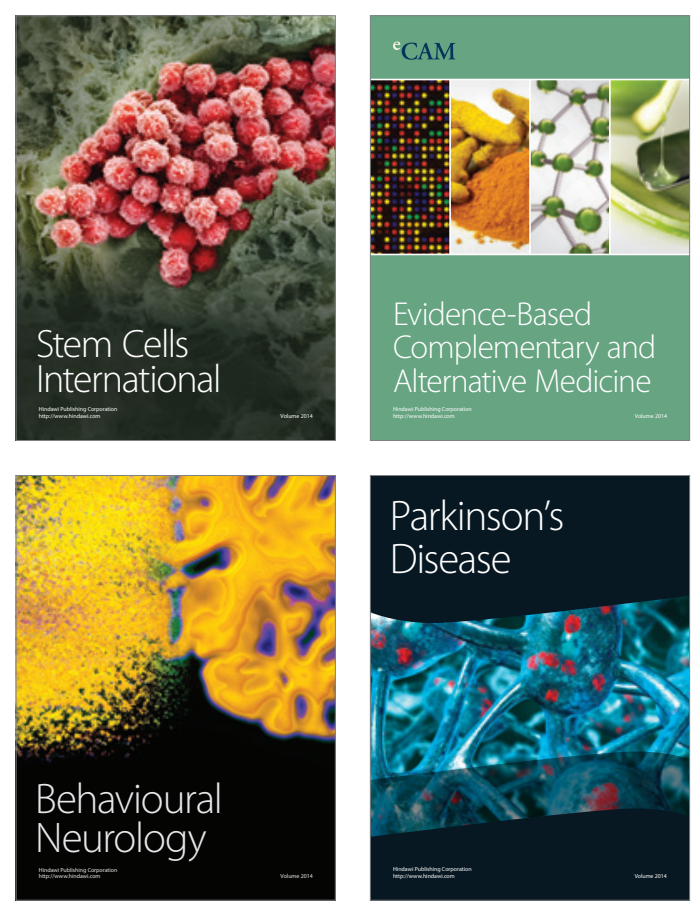

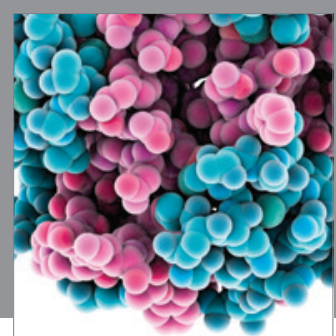

Journal of
Diabetes Research

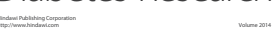

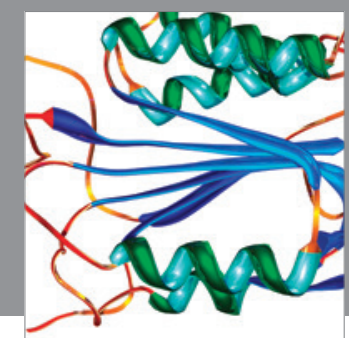

Disease Markers
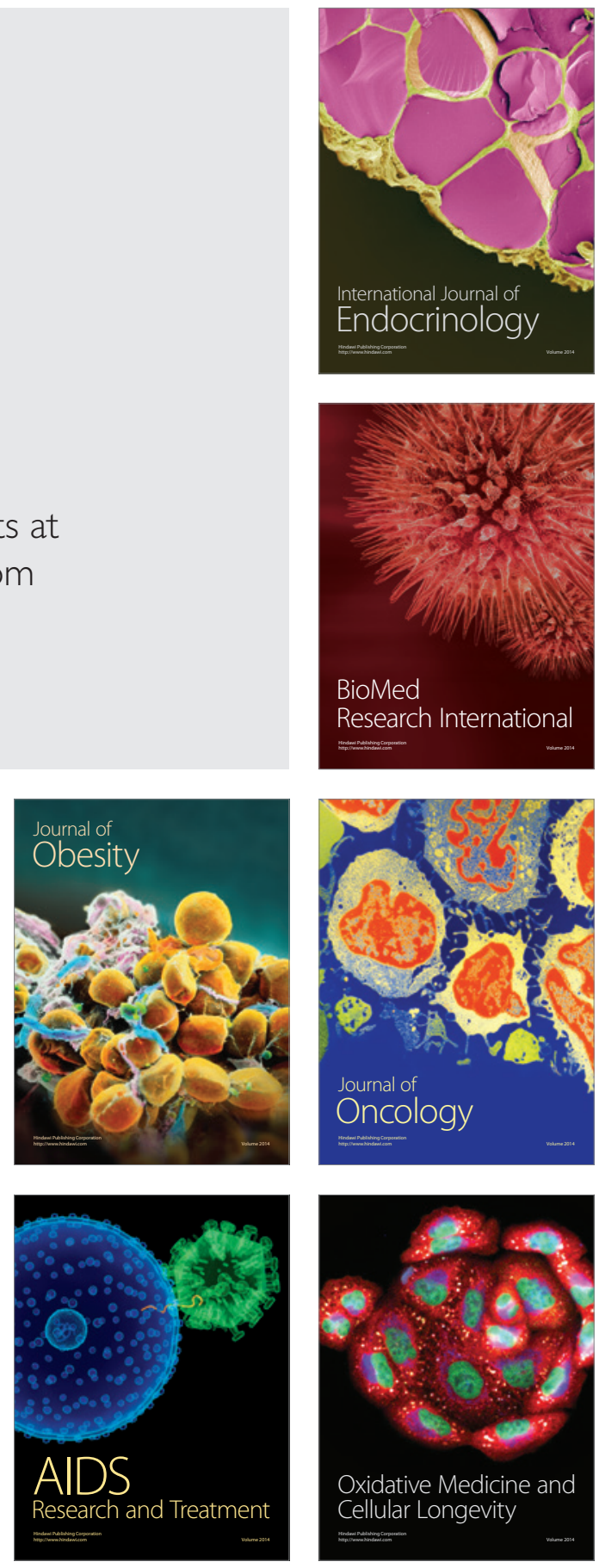